\title{
PREPARATION AND CHARACTERIZATION OF POLY (VINYL ALCOHOL)-POLY (VINYL PYRROLIDONE) MUCOADHESIVE BUCCAL PATCHES FOR DELIVERY OF LIDOCAINE HCL
}

\author{
NAPAPHAK JAIPAKDEEa,b, THANED PONGJANYAKUL ${ }^{a}$, EKAPOL LIMPONGSAa, ${ }^{a *}$
}

aDivision of Pharmaceutical Technology, Faculty of Pharmaceutical Sciences, Khon Kaen University, Khon Kaen, 40002, Thailand, bCenter for Research and Development of Herbal Health Products, Khon Kaen University, Khon Kaen, 40002, Thailand Email: ekapol@hotmail.com

Received: 20 Oct 2017, Revised and Accepted: 28 Nov 2017

\section{ABSTRACT}

Objective: The objectives of this study were to prepare and characterize a buccal mucoadhesive patch using poly (vinyl alcohol) (PVA), poly (vinyl pyrrolidone) (PVP) as a mucoadhesive matrix, Eudragit $\mathrm{S} 100$ as a backing layer, and lidocaine $\mathrm{HCl}$ as a model drug.

Methods: Lidocaine $\mathrm{HCl}$ buccal patches were prepared using double casting technique. Molecular interactions in the polymer matrices were studied using attenuated total reflectance-fourier transform infrared spectroscopy (ATR-FTIR), differential scanning calorimetry (DSC) and X-ray diffractometry. Mechanical and mucoadhesive properties were measured using texture analyzer. In vitro permeation of lidocaine $\mathrm{HCl}$ from the patch was conducted using Franz diffusion cell.

Results: Both of the free and lidocaine $\mathrm{HCl}$ patches were smooth and transparent, with good flexibility and strength. ATR-FTIR, DSC and X-ray diffractometry studies confirmed the interaction of PVA and PVP. Mechanical properties of matrices containing 60\% PVP were significantly lower than those containing 20\% PVP $\left({ }^{*} \mathrm{P}<0.05\right)$. Mucoadhesive properties had a tendency to decrease with the concentration of PVP in the patch. The patch containing $60 \%$ PVP had significantly lower muco-adhesiveness than those containing $20 \% \mathrm{PVP}\left({ }^{*} \mathrm{P}<0.05\right)$. In vitro permeation revealed that the pattern of lidocaine $\mathrm{HCl}$ permeation started with an initial fast permeation, followed by a slower permeation rate. The initial permeation fluxes follow the zero-order model of which rate was not affected by the PVP concentrations in the PVA/PVP matrix.

Conclusion: Mucoadhesive buccal patches fabricated with PVA/PVP were successfully prepared. Incorporation of PVP in PVA/PVP matrix affected the strength of polymeric matrix and mucoadhesive property of patches.

Keywords: Poly (vinyl pyrrolidone), Poly (vinyl alcohol), Lidocaine $\mathrm{HCl}$, Permeation, Buccal patch, Buccal drug delivery

(C) 2018 The Authors. Published by Innovare Academic Sciences Pvt Ltd. This is an open-access article under the CC BY license (http://creativecommons.org/licenses/by/4.0/) DOI: http://dx.doi.org/10.22159/ijap.2018v10i1.23208

\section{INTRODUCTION}

Buccal drug delivery has gained considerable attention as an alternative dosage form [1]. Numerous retentive buccoadhesive devices [2-6], were developed in order to solve the conventional dosage form limitations. Buccal mucoadhesive patches are preferable over the buccal tablets for their flexibility, and the patches tend to be less obtrusive and are more likely to be accepted by patients. [7].

Mucoadhesive patches for buccal mucosa administration may have a number of different designs $[7,8]$. These patches usually contain hydrophilic polymers that are able to form sticky hydrogels after getting in contact with water, and adhere to the buccal mucosa and the impermeable backing membrane [3]. The impermeable backing membrane is an important part to ensure the unidirectional drug release [9]. Materials with hydrophobicity, low water permeability and drug impermeability properties such as melted wax [10], ethyl cellulose [1, 4, 11], and Eudragit RL100 [12] have been used as a backing membrane. A wide range of polymers such as hydroxypropyl methylcellulose, carbopol, poly (vinyl alcohol) (PVA), and poly (vinyl pyrrolidone) (PVP) [13-17] have been employed as a matrix and mucoadhesive layer in buccal patches. In order to improve the film properties, including film-forming ability, mechanical and mucoadhesive properties, a combination of hydrophilic polymers is generally used.

This study will focus on the buccal mucoadhesive bilayered patches prepared with PVA and PVP as base matrix polymers. PVA is a wellknown, water-soluble polymer with high transparency and flexibility [18]. However, it has a moderate swelling and mucoadhesive properties $[14,19]$. PVP is a non-ionic, film-forming polymer. It has high swelling properties and has been used as coadjuvant to increase mucoadhesion $[7,16]$. The combination of PVA and PVP leads to a more versatile property matrixes. The physical, mechanical and thermal properties of PVA and PVP matrixes can be modulated by varying the PVA/PVP ratio. These two polymers and their blends have been used in numerous applications, including biomedical films [20], transdermal [21, 22] and buccal patches $[13,14]$. Nevertheless, to the best of our knowledge, the relationships between PVA/PVP ratios and the mucoadhesion property of buccal patches, as well as the permeation behaviour of the hydrophilic drug through the mucosa are not well established.

Lidocaine $\mathrm{HCl}$ was used as a hydrophilic model drug. It is very soluble in water [23]. It has been reported that lidocaine $\mathrm{HCl}$ diffused passively through porcine buccal membrane [24]. Lidocaine $\mathrm{HCl}$ has a primary indication as a local anaesthetic agent when applied topically $[25,26]$. There are several pharmaceutical dosage forms of lidocaine $\mathrm{HCl}$ available on the market, i.e., solution for injection or infusion, nasal spray, oral gel and transdermal patch $[24,26]$. Several authors have developed the buccal mucoadhesive systems of lidocaine and/or lidocaine $\mathrm{HCl}[25,27-29]$. However, in previous literature, no attempt has been taken to formulate lidocaine $\mathrm{HCl}$ buccal patches simply using PVA and PVP along with Eudragit S100.

Being different from the earlier investigations, the objective of this study was to prepare a buccal mucoadhesive patch using PVA and PVP as a mucoadhesive and drug reservoir layer. Eudragit S100 was used as a backing layer. Lidocaine $\mathrm{HCl}$ was used as a model drug. The effects of PVA/PVP ratios and lidocaine $\mathrm{HCl}$ addition on the appearance, thickness and mechanical properties of polymer matrices were investigated. Molecular interaction, thermal behaviour and solid-state characteristics of the drug within the polymer matrices were studied. The mucoadhesive properties of buccal patches containing lidocaine $\mathrm{HCl}$ and the in vitro permeation of lidocaine $\mathrm{HCl}$ were also evaluated.

\section{MATERIALS AND METHODS}

\section{Materials}

Poly (vinyl alcohol) (PVA) was purchased from Ajax Finechem Pty Ltd, Seven Hills, Australia. Poly (vinyl pyrrolidone) (PVP) K30 was obtained 
from K. Science Center and Medical, Khon Kaen, Thailand. Lidocaine $\mathrm{HCl}$ was purchased from S. Tong Chemicals, Bangkok, Thailand. Dibutyl phthalate (DBP) was obtained from Merck-Schuchardt, Hohenbrunn, Germany. Methacrylic acid copolymer type B (Eudragit S100) was gifted from Evonik Industries AG, Essen, Germany. Deionized water was used throughout the studies. All chemicals were of reagent or highperformance liquid chromatography (HPLC) grade.

\section{Preparation of blank and lidocaine $\mathrm{HCl}$ matrices}

Blank matrices were composed of different concentrations of PVA and PVP (table 1) which were prepared by a plate casting method [4, 15]. PVA was weighted and dissolved in boiled water, while PVP was weighted and dissolved in hot water to yield solutions at $12 \% \mathrm{w} / \mathrm{w}$. The required amount of each solvent was mixed to get the polymer solution. The resultant solution was poured into a polypropylene plate $(12 \mathrm{~cm} \times 12 \mathrm{~cm})$, which was then oven-dried at $55^{\circ} \mathrm{C}$ for $12 \mathrm{~h}$. In the case of lidocaine $\mathrm{HCl}$ matrices, lidocaine $\mathrm{HCl}(20 \%$ of dry weight of polymers) was incorporated into the polymer solution. The clear drug-polymer solution was then cast onto the plate and subsequently oven-dried as mentioned above. The dry matrices were packed in aluminium foil and kept in a desiccator until used.

\section{Evaluation of blank and lidocaine $\mathrm{HCl}$ matrices}

\section{Appearance and thickness}

The appearance and thickness of matrix specimen (rectangular shape, $0.5 \mathrm{~cm} \mathrm{x} 4 \mathrm{~cm}$ ) were observed and measured at five different places using a dial thickness gauge (Peacock, Labtek, USA). The average of the five values was calculated.

\section{Molecular interaction}

Attenuated total reflectance-Fourier transform infrared (ATRFTIR) spectroscopy

The spectra (4000 to $650 \mathrm{~cm}-1$ at a resolution of $4 \mathrm{~cm}-1$ ) of the samples were recorded using an ATR-FTIR spectrophotometer (Spectrum One, Perkin Elmer, Norwalk, CT). Each sample was cut and placed on a ZnSe prism of a sample holder.

\section{Thermal study}

Differential scanning calorimetry (DSC) curves of the samples were recorded using a differential scanning calorimeter (DSC822, Mettler Toledo, Switzerland). Each sample (3-5 mg) was accurately weighed into a 40- $\mu \mathrm{l}$ open aluminium pan. The measurements were performed over $30-300^{\circ} \mathrm{C}$ at a heating rate of $10^{\circ} \mathrm{C} / \mathrm{min}$.

\section{$\mathrm{X}$-ray diffractometry}

$\mathrm{X}$-ray diffraction (XRD) measurements of samples were performed on an X-ray diffractometer (D8 ADVANCE diffractometer, Bruker, Germany). The measurement conditions were $\mathrm{Cu}$ radiation generated at $40 \mathrm{kV}$ and $40 \mathrm{~mA}$ as an X-ray source, angular 5-50 ${ }^{\circ}$ $(2 \theta)$, and step angle $0.02^{\circ}(2 \theta) / \mathrm{s}$.

\section{Moisture absorption}

A weighed matrix $(1 \mathrm{~cm} \mathrm{x} 1 \mathrm{~cm})$ kept in a desiccator with silica gel for $24 \mathrm{~h}$ was taken out and transferred to a desiccator containing saturated sodium chloride solution (relative humidity $75 \%$ ) at $25^{\circ} \mathrm{C}$. After equilibrium was attained, the matrix was taken out and weighed. Moisture absorption capacity was calculated based on the change in the weight with respect to the initial weight of the matrix.

\section{Mechanical properties}

Mechanical properties which are ultimate tensile strength (UTS), percent elongation at break (\%E) and Young's modulus (YM) were determined following the method modified from Okhamafe and York [30] using a texture analyzer (TA. XT plus, Stable Micro Systems, UK) with a 50-N load cell equipped with a miniature tensile grip. The cross-head speed was controlled at $10 \mathrm{~mm} / \mathrm{min}$. The UTS and percent elongation at break were calculated from equations (1) and (2), respectively.

$$
\text { UTS }=\frac{\text { breaking load }}{\text { cross }- \text { sectional area of specimen }}
$$

$\% \mathrm{E}=\frac{\text { length at breaking point }- \text { original length of specimen }}{\text { original length of specimen }} \times 100$

\section{Preparation of lidocaine $\mathrm{HCl}$ buccal patches}

Lidocaine $\mathrm{HCl}$ buccal patches (lidocaine $\mathrm{HCl}$ matrices with backing) were prepared using double casting technique [3]. An ethanolic solution of the backing layer composed of Eudragit S100 and DBP $(40 \%)$ as a plasticizer was poured into a glass plate (diameter $=10$ $\mathrm{cm}$ ) and subsequently oven-dried at $55^{\circ} \mathrm{C}$ for $2 \mathrm{~h}$. The second matrix solution composed of PVA, PVP and lidocaine $\mathrm{HCl}$ (table 1) was immediately cast on top of the pre-cast dried Eudragit S100 backing layer and then oven-dried at $55{ }^{\circ} \mathrm{C}$ for $12 \mathrm{~h}$. The dried patches were packed in aluminium foil and kept in a desiccator until used. The patches were cut into a size of $20 \mathrm{~mm}$ diameter, stored in a desiccator until further use.

\section{Evaluation of lidocaine $\mathrm{HCl}$ buccal patches}

\section{Determination of lidocaine $\mathrm{HCl}$ content in patches}

A known weight of licocaine $\mathrm{HCl}$ matrices was dissolved and diluted in water. The licocaine $\mathrm{HCl}$ content was determined by an HPLC system as described below.

\section{Determination of mucoadhesive properties of patches}

The mucoadhesive properties of the patches were measured using a texture analyzer (TA. XT plus, Stable Micro Systems, UK) with a 50-N load cell equipped with a bioadhesive test rig. The patch was attached to a $10-\mathrm{mm}$ diameter cylindrical probe using a two-sided adhesive tape. The esophageal mucosa of the pig was also obtained from a local slaughterhouse (Non-Muang Village, Khon Kaen, Thailand). The mucosal membrane from the porcine esophagus (about $2 \mathrm{~cm} \times 2 \mathrm{~cm}$ ) without heat treatment and elimination of the connective tissue that had been hydrated with $\mathrm{pH} 6.8$ isotonic phosphate buffer (IPB) for $20 \mathrm{~min}$ was placed on the stage of bioadhesive holder and gently blotted with tissue paper to remove excess water on the surface of the mucosal membrane. Next, $100 \mu \mathrm{l}$ of $\mathrm{pH}$ 6.8 IPB was pipetted onto the membrane surface before testing. The probe and attached patches were moved down at a constant speed of $1 \mathrm{~mm} / \mathrm{s}$ with $0.5-\mathrm{N}$ contact force and 2-min contact time. Immediately afterwards, the probe was moved upwards with a constant speed of $0.5 \mathrm{~mm} / \mathrm{s}$. The relationship between the force and patch displacement was plotted. The maximum detachment force $\left(F_{\max }\right)$ and work of adhesion $\left(W_{\text {ad, }}\right.$ the area under the force versus distance curve) were calculated using the Texture Exponent 32 program version 4.0.9.0 (Stable Micro Systems).

\section{In vitro permeation study of lidocaine $\mathrm{HCl}$ from patches}

\section{Mucosa preparation}

The porcine oesophagal mucosa was employed in this study because it has a lipid composition similar to that of the porcine buccal mucosa, but requires a simpler preparation method [31]. The esophageal mucosa was obtained from crossbred pigs (hybrid kinds of Duroc JerseyLandrace-Large White) that weighed between 80-100 kg and was purchased from a local slaughterhouse (Non-Muang Village, Khon Kaen, Thailand). The porcine esophageal tube was opened longitudinally and immersed in $0.9 \%$ sodium chloride at $60^{\circ} \mathrm{C}$ for $1 \mathrm{~min}$ [31, 32]. The epithelium was then peeled away from the connective tissue.

The in vitro permeation of lidocaine $\mathrm{HCl}$ from the patch through the porcine esophageal mucosa was conducted using a Franz diffusion cell with a diffusion area of $0.636 \mathrm{~cm} 2$ (Crown Glass Company, Q1 Branchburg, NJ). The system was connected to a water bath maintained at a temperature of $37.0 \pm 0.5{ }^{\circ} \mathrm{C}$. The thickness of a mucosa was measured using a dial thickness gauge (Peacock, Labtek, Scotts Valley, CA). The mucosa was then mounted on the diffusion cell, which contained $\mathrm{pH} 6.8 \mathrm{IPB}$ as a receptor medium. The lidocaine $\mathrm{HCl}$ patch was placed over the mucosa and the cell was then fixed and tightly fastened with a clamp. At predetermined times, $0.5-\mathrm{ml}$ samples were taken from the receptor compartment and equal volumes IPB were immediately added after each sampling. The concentration of lidocaine $\mathrm{HCl}$ was 
analyzed by HPLC. The cumulative amount of drug that permeated the mucosa was plotted against time.

\section{Data analysis}

The lidocaine $\mathrm{HCl}$ permeation rates from the patches were analyzed using both zero-order and Higuchi models [33], which can be expressed as equations 3 and 4, respectively, as follows:

$$
Q=K_{0} t \ldots \ldots . .(3)
$$

and

$$
Q=K_{\mathrm{H}} \mathrm{t}^{1 / 2} \ldots \ldots \ldots \ldots(4)
$$

Where $Q$ is the amount of lidocaine $\mathrm{HCl}$ permeated, $t$ is time, and $K_{0}$ and $K_{\mathrm{H}}$ are the zero-order and Higuchi permeation rates, respectively.

\section{HPLC analysis}

Lidocaine $\mathrm{HCl}$ content was determined using an HPLC system (Perkin-Elmer, MA) consisting of a UV/VIS detector (model 785A) and a pump (series $200 \mathrm{LC}$ ). The chromatographic separation was achieved on a Hypersil Gold C-18 column $(250 \mathrm{~mm} \times 4.6 \mathrm{~mm}, 5 \mu \mathrm{m}$; Thermo Electron Corporation, USA) with a flow rate of $1 \mathrm{ml} / \mathrm{min}$ and UV detection at $254 \mathrm{~nm}$. The mobile phase consisted of methanol, acetic acid, triethylamine and water at a volume ratio of 55: 1.5: 0.5: 43. The retention time of lidocaine was approximately $4.3 \mathrm{~min}$. The standard curve was linear over a concentration range of 5 to 120 $\mu \mathrm{g} / \mathrm{ml}$ with an $R 2$ value $>0.99$. The day-to-day relative standard deviations (RSD) for this assay were less than $5 \%$.

\section{Statistical analysis}

Each experiment was repeated at least three times. The results are expressed as the mean \pm SD One-way analysis of variance was used to test the statistical significance of differences among groups. Statistical significance of the differences of the means was determined by Student's t-test. All statistical tests were run using the SPSS program for MS Windows, release 19 (SPSS (Thailand) Co. Ltd., Bangkok, Thailand). The significance was determined with $95 \%$ confident limits $(\alpha=0.5)$ and was considered significant at a level of $\mathrm{P}$ less than 0.05 .

\section{RESULTS AND DISCUSSION}

\section{Blank and lidocaine $\mathrm{HCl}$ matrices}

Both of the blank and lidocaine $\mathrm{HCl}$ matrices were prepared by a solvent casting method using an aqueous solution of $12 \%$ polymer. The result shows that the blank matrix made from PVA alone was very hard, while the matrix made from PVP alone was very brittle. On the contrary, the matrices prepared from PVA and PVP, at all concentrations investigated, were flexible, clear with a smooth surface and ready to be peeled off from the mould. According to Preis et al. [3], the polymer solid content of $10-15 \%$ was desirable to yield the matrix films with a suitable thickness that could easily be peeled off from the release liner. As shown in table 1, the thicknesses of formulations F1, $\mathrm{F} 2$ and $\mathrm{F} 3$ were comparable $(\mathrm{P}>0.05)$ and were in the average range of 125 to $130 \mu \mathrm{m}$. The matrix thickness is an important factor affecting the strength, flexibility, swelling, drug loading capacity and physicochemical stability of the buccal patches [1]. All of the lidocaine $\mathrm{HCl}$ matrices, formulations LDC-F1, LDC-F2 and LDC-F3, were also clear, smooth and uniform, similar to the blank matrices. The clearness and transparency of lidocaine $\mathrm{HCl}$ matrices suggest that lidocaine $\mathrm{HCl}$ was solubilized in the polymer matrix. The thicknesses of lidocaine $\mathrm{HCl}$ matrices were in the average range of 136 to 142 $\mu \mathrm{m}$ (table 1) which were not different from those of the matrix formulations ( $\mathrm{P}>0.05)$. Therefore, the addition of lidocaine $\mathrm{HCl}, 20 \%$ of polymers dry weight, had no effect on the physical appearance of the lidocaine $\mathrm{HCl}$ matrices.

\begin{tabular}{|c|c|c|c|c|c|c|c|}
\hline \multirow[t]{2}{*}{ Formulation } & \multicolumn{2}{|c|}{ Concentration (\%) } & \multirow[t]{2}{*}{ LDC } & \multirow[t]{2}{*}{ Thickness $(\mu \mathrm{m})^{a}$} & \multirow[t]{2}{*}{ UTS (MPa) ${ }^{a}$} & \multirow[t]{2}{*}{$\% E(\%)^{a}$} & \multirow[t]{2}{*}{ YM (MPa) } \\
\hline & PVA & PVP & & & & & \\
\hline F1 & 80 & 20 & - & $125 \pm 18$ & $59.2 \pm 7.0$ & $121.7 \pm 54.0$ & $4.6 \pm 0.4$ \\
\hline F2 & 60 & 40 & - & $128 \pm 27$ & $54.4 \pm 6.4$ & $130.2 \pm 61.5$ & $4.0 \pm 0.5$ \\
\hline F3 & 40 & 60 & - & $130 \pm 31$ & $40.4 \pm 2.7$ & $40.1 \pm 6.0$ & $2.6 \pm 0.3$ \\
\hline LDC-F1 & 80 & 20 & $20 \%$ & $136 \pm 14$ & $29.8 \pm 2.9$ & $268.8 \pm 60.9$ & $2.9 \pm 0.3$ \\
\hline LDC-F2 & 60 & 40 & $20 \%$ & $137 \pm 13$ & $19.2 \pm 1.4$ & $258.1 \pm 48.8$ & $2.1 \pm 0.2$ \\
\hline LDC-F3 & 40 & 60 & $20 \%$ & $142 \pm 13$ & $9.0 \pm 0.7$ & $261.2 \pm 61.1$ & $1.1 \pm 0.3$ \\
\hline
\end{tabular}

Table 1: Thickness and mechanical properties of blank and lidocaine $\mathrm{HCl}$ matrices as a function of PVA and PVP concentrations

UTS: ultimate tensile strength, \%E: percent elongation at break, YM: Young's modulus, a mean \pm SD, $n=5$.

\section{Molecular interactions}

Molecular interactions between PVA and PVP in the blank and lidocaine $\mathrm{HCl}$ matrices were investigated using ATR-FTIR spectroscopy and XRD analysis.

\section{ATR-FTIR}

The ATR-FTIR spectra of PVA and PVP powders, PVA/PVP matrix (F3), lidocaine $\mathrm{HCl}$ matrix containing 60\% PVP (LDC-F3) and lidocaine $\mathrm{HCl}$ powder are shown in fig. 1. In ATR-FTIR spectrum of PVA powder (fig. 1a), the wide peak located at $3271 \mathrm{~cm}-1$ is for the $\mathrm{O}-\mathrm{H}$ stretch vibration. Absorption for asymmetrical stretching vibration and symmetrical stretching vibration of $\mathrm{CH}_{2}$ occurred at 2932 and $2908 \mathrm{~cm}-1$, respectively. The two peaks of 1414 and 1326 $\mathrm{cm}-1$ are attributed to the coupling of the secondary $0-\mathrm{H}$ in-plane bending and the $\mathrm{C}-\mathrm{H}$ wagging vibrations. Absorption at $1085 \mathrm{~cm}-1$ was produced by C-O stretching vibration [34]. The main absorption bands of PVP powder were observed at 1661, 1420, 1371 and 1283 $\mathrm{cm}-1$ (fig. 1b). These bands were assigned as $\mathrm{C}=0$ symmetric stretching, $\mathrm{CH}_{2}$ bending, $\mathrm{O}-\mathrm{H}$ bending (in-plane) and $\mathrm{C}-\mathrm{H}$ deformation, respectively [18].

The PVA/PVP matrix spectra (fig. 1c, d and e) were similar to those of PVA and PVP powders. Nevertheless, the differences between the relative ATR-FTIR absorbance of PVA and PVP powders can be seen at $3271 \mathrm{~cm}-1$ and in the region of $1800-1500$ and $1260-1000 \mathrm{~cm}-1$. Blending of PVP with PVA caused the $\mathrm{O}-\mathrm{H}$ stretching peak of PVA to move to higher wavenumbers: $3298-3280 \mathrm{~cm}-1$ and the C-O stretching of PVA shifted from $1085 \mathrm{~cm}-1$ to $1091-1089 \mathrm{~cm}-1$. Moreover, the $\mathrm{C}=0$ stretching of PVP shifted from $1660 \mathrm{~cm}-1$ to $1655-1651 \mathrm{~cm}-1$. These results indicate the intermolecular hydrogen bonding between hydroxyl groups of PVA and carbonyl groups of PVP. This result was in agreement with the previous report [35]. PVP contains a proton-accepting carbonyl moiety in its pyrrolidone ring, whereas hydroxyl groups as side groups are presented in the PVA. In PVP/PVA matrices, the hydrogen bonding interaction is able to occur between these two moieties [36].

As shown in fig. 1g, lidocaine $\mathrm{HCl}$ powder showed a N-H stretching at $3383 \mathrm{~cm}-1$, a C- $\mathrm{H}$ stretching at $3011 \mathrm{~cm}-1$, an amide I ( $\mathrm{C}=0)$ at 1654 $\mathrm{cm}-1$ and an amide II (C-N) at $1472 \mathrm{~cm}-1$. These values are in good agreement with the results obtained in other studies $[29,37,38]$. Regardless of the PVP content, the ATR-FTIR spectrum of lidocaine $\mathrm{HCl}$ matrices showed no absence of any functional peak in the spectra, revealing that there is no significant chemical interaction between the drug and polymers. The example of the spectrum of lidocaine $\mathrm{HCl}$ matrix prepared with $60 \%$ PVP is shown in fig. 1f. Additionally, there were no new bands observed in drug-polymer matrices, which confirms that no new chemical bonds were formed between lidocaine $\mathrm{HCl}$ and polymers. 


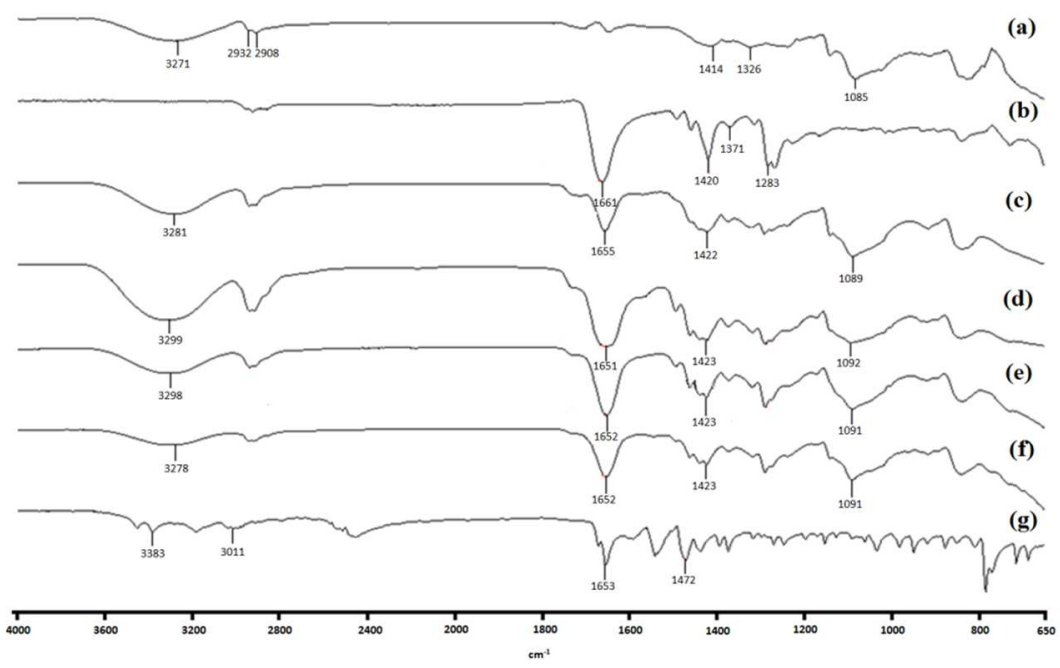

Fig. 1: ATR-FTIR spectra of PVA powder (a), PVP powder (b), PVA/PVP matrices containing 20\% PVP (c), 40\% PVP (d), $60 \%$ PVP (e), lidocaine $\mathrm{HCl}$ matrix containing $60 \% \mathrm{PVP}$ (f) and lidocaine $\mathrm{HCl}$ powder (g)

\section{Thermal study}

The DSC thermograms of the PVA and PVP powders and PVA/PVP matrices are presented in fig. 2. The PVA powder showed an endothermic peak at about $213.8{ }^{\circ} \mathrm{C}$ (fig. 2a). This was due to the melting of the crystalline phase present in this polymer [36]. Incorporation of $20 \% \mathrm{w} / \mathrm{w}$ PVP into the PVA had no effect on the DSC pattern as the PVA endothermic peak was at $213.8^{\circ} \mathrm{C}$ (fig. 2b). A shift of this PVA endothermic peak to lower temperature $\left(205.3^{\circ} \mathrm{C}\right)$ was observed for $40 \%$ PVP/PVA matrix, and a disappearance of this peak occurred at $60 \%$ PVP/PVA matrix (fig. 2c-d). However, the endothermic peak of their physical mixtures was present at almost the same temperature $\left(213.7,211.0,213.9{ }^{\circ} \mathrm{C}\right.$ for 20,40 and $60 \%$ w/w PVP to PVA, respectively; data not shown). This was presumably due to the decreases in the degree of crystallinity and crystallization rate of PVA by the PVP [36]. In addition, Seabra and De Oliveira [20] reported that the depression in melting temperature peak of the crystalline phase of PVA by PVP indicated the specific multiple hydrogen bonding interactions between the two polymers.

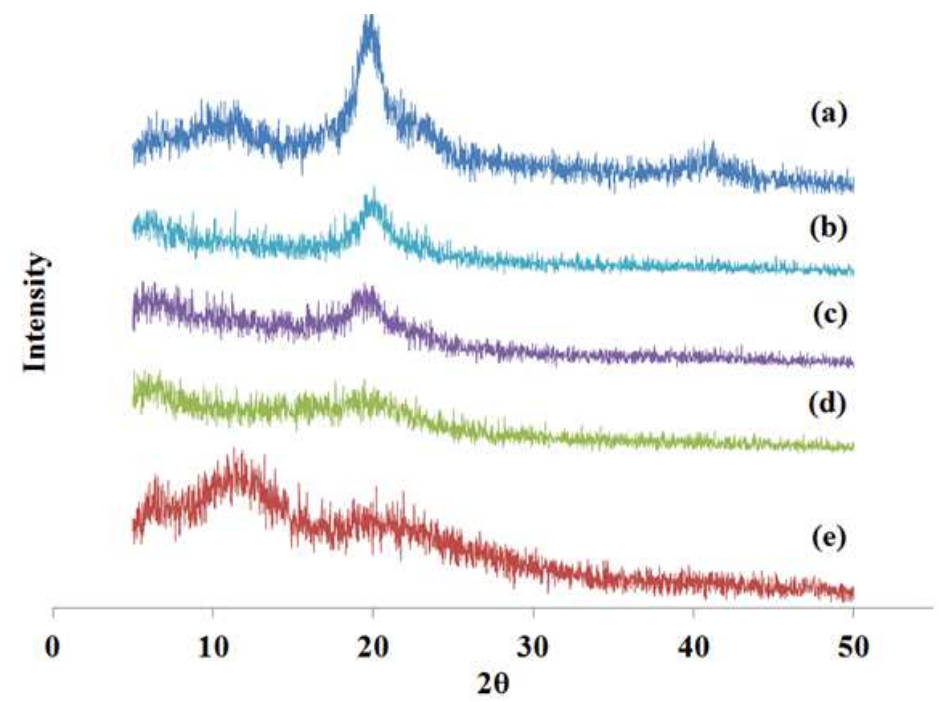

Fig. 2: XRD patterns of PVA powder (a), PVA/PVP matrices containing 20\% PVP (b), $40 \%$ PVP (c), $60 \%$ PVP (d) and PVP powder (e)

The DSC curves of the lidocaine $\mathrm{HCl}$ and lidocaine $\mathrm{HCl}$ matrices are presented in fig. 3. Lidocaine $\mathrm{HCl}$ showed an endothermic peak at $77.9^{\circ} \mathrm{C}$ followed by a boiling and volatilization peak starting from $188^{\circ} \mathrm{C}$ (fig. 3a). The endothermic peak of lidocaine $\mathrm{HCl}$ was not present in the DSC patterns of lidocaine $\mathrm{HCl}$ matrices, irrespective of PVP concentration in the matrix (fig. 3b-d). This is presumably explained by the fact that lidocaine $\mathrm{HCl}$ is being solubilized in the PVA/PVP matrices. This hypothesis was supported by the DSC thermograms of the physical mixture of lidocaine $\mathrm{HCl}$, PVP and PVA (data not shown) and other characterization technique shown later.
DSC curves of the lidocaine $\mathrm{HCl}$ matrices revealed that incorporation of lidocaine $\mathrm{HCl}$ (at $20 \% \mathrm{w} / \mathrm{w}$ of polymer) into the PVA/PVP matrices caused a shift of PVA endothermic peak to lower temperature at $20 \%$ and $40 \%$ PVP and disappearance of the endothermic peak at 60\% PVP (fig. 3b-d). These presumably suggested that lidocaine $\mathrm{HCl}$ may act as the plasticizer. It is known that plasticizers generally affect the thermal and mechanical properties of a polymer matrix. Similar findings were observed by Aitken-Nichol et al. [39] who found that the glass transition temperature of the melting endothermic peak of Eudragit E100 films was lower with the addition lidocaine $\mathrm{HCl}$. 


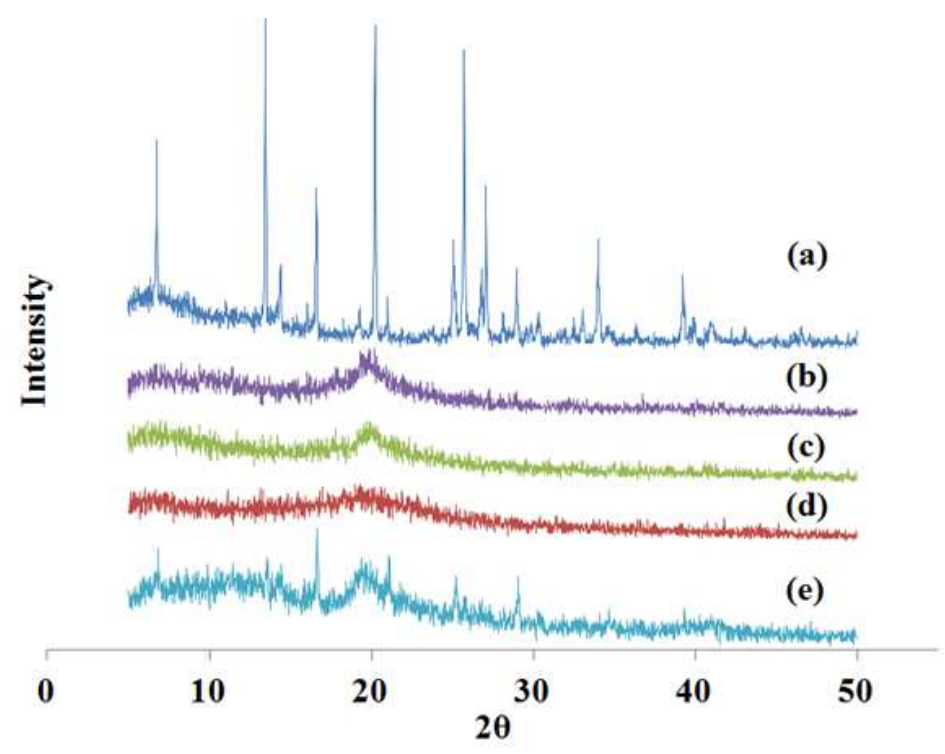

Fig. 3: XRD patterns of lidocaine $\mathrm{HCl}$ powder (a), lidocaine $\mathrm{HCl}$ matrices containing $20 \%$ PVP (b), 40\% PVP (c), $60 \%$ PVP (d) physical mixture of lidocaine $\mathrm{HCl}, 40 \%$ PVP-PVA (e)

\section{$\mathrm{X}$-ray diffractrometry}

The XRD patterns of the same materials support the ATR-FTIR and DSC results. XRD measurement is a versatile, non-destructive technique that reveals the crystallographic structure of materials and can be used to investigate the complex formation between the polymers. The XRD patterns of PVA and PVP powders and PVA/PVP matrices are shown in fig. 4. The XRD pattern of PVA powder exhibits diffraction peak angle at $2 \theta=10.5^{\circ}, 19.8^{\circ}$ and $41.0^{\circ}$ (fig. 4a). The strong and broad peak at $19.8^{\circ}$ corresponds to the $\left(\begin{array}{lll}1 & 0 & 1\end{array}\right)$ reflection, a plane which contains the extended planar zig-zag chain direction of the crystallities $[40,41]$. The XRD pattern of PVP powder in fig. 4e exhibits amorphous features characterized by two halos centered at $2 \theta=11.7^{\circ}$ and $20.2^{\circ}$.

For the PVA/PVP matrices, the sharp peak was clearly observed in the XRD patterns of the matrices with high PVA content (fig. $4 \mathrm{~b}$ and 4c). The intensity of PVA pattern decreased with the addition of PVP. This was due to the amorphous nature of the matrix that increased with the addition of PVP [35]. The PVA/PVP matrices containing $60 \%$ PVP exhibited the highest amorphous nature as the peak at $2 \theta$ $=20.0^{\circ}$ was small and broad (fig. 4d). Based on these findings, it could be implied that the degree of crystallization of PVA decreased with the increase of PVP content [42].

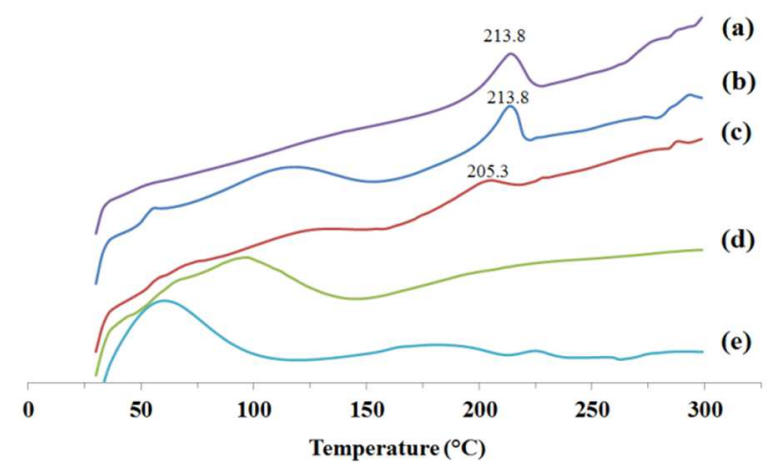

Fig. 4: DSC thermograms of PVA powder (a), PVA/PVP matrices containing 20\% PVP (b), 40\% PVP (c), 60\% PVP (d), and PVP powder (e)

Fig. 5 reveals the XRD patterns of lidocaine $\mathrm{HCl}$, lidocaine $\mathrm{HCl}$ matrices and physical mixture of lidocaine $\mathrm{HCl}$ and $40 \% \mathrm{PVP}$. Lidocaine $\mathrm{HCl}$ was highly crystalline in nature as shown by numerous characteristic sharp peaks in its XRD pattern. However, the XRD patterns of lidocaine $\mathrm{HCl}$ matrices (fig. 5b-d) showed one broader peak which were similar to those of PVA/PVP matrices (fig. 4b-d). There was no crystalline pattern corresponding to that of lidocaine $\mathrm{HCl}$ observed. The crystallinity nature of lidocaine $\mathrm{HCl}$ in lidocaine $\mathrm{HCl}$ matrices was absent, whereas their physical mixture exhibited a sharp crystalline peak (fig. 5e). This suggested that lidocaine $\mathrm{HCl}$ embedded in the matrix as a solution. In addition, the absence of drug indicated peaks in the DSC patterns and matrix physical clarity characteristic. These results assured that lidocaine $\mathrm{HCl}$ was dispersed with the polymer network as a molecular dispersion level. Previous studies showed that lidocaine $\mathrm{HCl}$ was present in the amorphous condition in a hydroxypropyl cellulose film [27] and carbopol film [29].

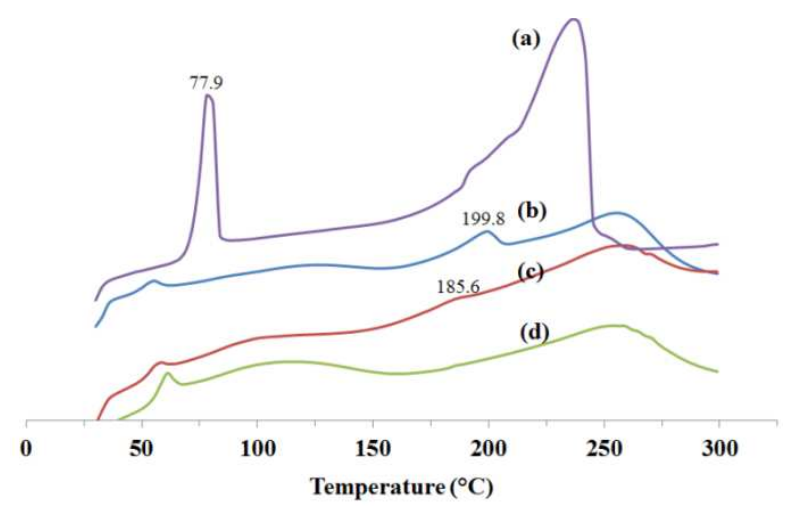

Fig. 5: DSC thermograms of lidocaine $\mathrm{HCl}$ powder (a) and lidocaine HCl matrices containing 20\% PVP (b), 40\% PVP (c) and $60 \%$ PVP (d)

\section{Moisture absorption}

Moisture absorption study provides information regarding the stability of the formulation. Low level of moisture absorption can protect the materials from microbial contaminations and bulkiness of the polymer matrices [4, 43]. The effects of PVA and PVP concentration on moisture absorption of blank matrices were shown in fig. 6. The moisture absorption of blank matrices containing PVP at $20 \%$ and $40 \%$ were comparable. However, the moisture absorption of a matrix containing $60 \%$ PVP was significantly higher than that of the 
one containing 20\% PVP ( $\left.{ }^{\mathrm{P}}<0.05\right)$. The relationship between the PVP concentration and moisture absorption blank matrices with a high coefficient of determination ( $R 2$ of 0.9965 ) was shown. It is obvious that the increase of PVP concentration resulted in the increased moisture absorption of blank matrices. It is well known that PVA is soluble in water while PVP is hygroscopic and freely soluble in water, indicating that PVP has more hydrophilicity [44]. The increase of PVP content could lead to the higher hydrophilic matrix, leading to the high affinity for water and inducing the higher moisture uptake [30].
The effects of lidocaine $\mathrm{HCl}$ on moisture absorption of lidocaine $\mathrm{HCl}$ matrices were shown in fig. 6. The moisture absorption of matrices increased with lidocaine $\mathrm{HCl}$ addition. Significant effects of lidocaine $\mathrm{HCl}$ addition on the matrix moisture absorption were shown, irrespective of the PVP concentration in the matrices $(* \mathrm{P}<0.05)$. Lidocaine $\mathrm{HCl}$ is freely soluble in water [37]. Incorporation of lidocaine $\mathrm{HCl}$ into the matrix led to an increase in the hydrophilic property, which affected the moisture absorption of the matrix.

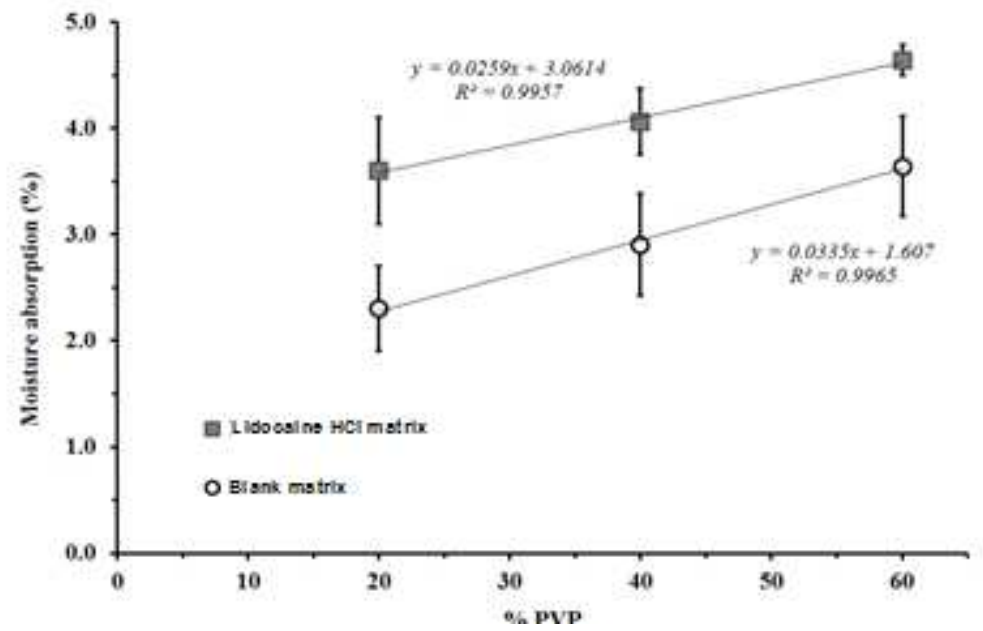

Fig. 6: Effect of PVP concentration on moisture absorption of blank and lidocaine $\mathrm{HCl}$ matrices $(\mathrm{mean} \pm \mathrm{SD}, n=5)$

\section{Mechanical properties}

Selection of polymeric matrix as potential buccal mucoadhesive system required knowledge of mechanical properties of the matrix. Therefore, the mechanical properties of blank matrices prepared from various ratios of PVA and PVP were characterized and presented in table 1. The ultimate tensile strength (UTS), percent elongation at break (\%E) and Young's modulus (YM) of blank matrices containing PVP at $20 \%$ and $40 \%$ were not different. However, the UTS, \%E and YM of a blank matrix containing 60\% PVP were significantly lower than those of blank matrices containing PVP at $20 \%$ and $40 \%(* \mathrm{P}<0.05)$.

The relationships between the PVP concentration and UTS and YM of blank matrices with a high coefficient of determinations ( $R 2$ of 0.9243 and 0.9478 , respectively) are shown in fig. 7. It is obvious that the increase of PVP concentration resulted in the decreased UTS and YM of blank matrices. Based on the results of ATR-FTIR spectroscopy, the hydroxyl groups of PVA and the pyrrolidone rings of PVP [36] may have a hydrogen-bonding interaction, resulting in the decrease in the inter-molecular forces between polymer chains of PVA, leading to the decreases of the UTS and YM.

The effects of lidocaine $\mathrm{HCl}$ on mechanical properties of lidocaine $\mathrm{HCl}$ matrices were investigated and shown in table 1 . The addition of lidocaine $\mathrm{HCl}$ had effects on the mechanical properties of the lidocaine $\mathrm{HCl}$ matrix. The UTS and YM of PVA/PVP matrices decreased significantly when lidocaine $\mathrm{HCl}$ was added to all concentrations of lidocaine $\mathrm{HCl}$ matrices $\left({ }^{*} \mathrm{P}<0.05\right)$. However, the percent elongation at break of lidocaine $\mathrm{HCl}$ matrices at all ratios increased significantly $\left({ }^{*} \mathrm{P}<0.05\right)$. From XRD and DSC studies, it was confirmed that lidocaine $\mathrm{HCl}$ was dissolved as a solution in the matrices. Therefore, lidocaine $\mathrm{HCl}$ as molecular dispersion, may act as a plasticizer which resulted in the increase of $\% \mathrm{E}$ of the matrix.

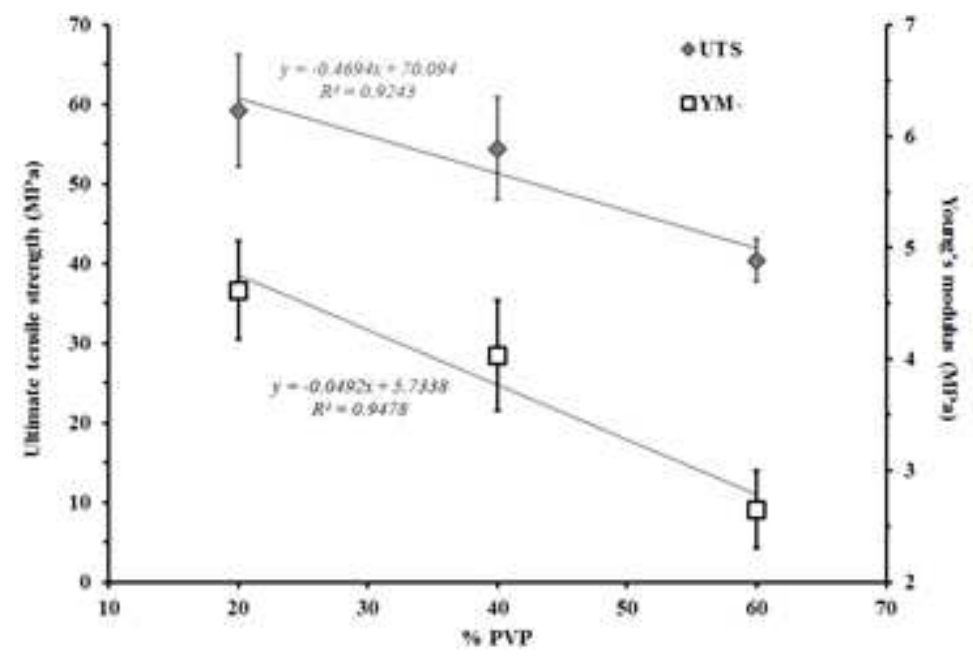

Fig. 7: Effects of PVP concentration on ultimate tensile strength (UTS) and Young's modulus (YM) matrices of PVA/PVP (mean \pm SD, $n=5$ ) 


\section{Lidocaine $\mathrm{HCl}$ patches}

Lidocaine $\mathrm{HCl}$ patches (LDC-P1, LDC-P2 and LDC-P3) were prepared by laminating one side of formulation LDC-F1, LDC-F2 and LDC-F3 with a water impermeable backing layer for unidirectional drug release. An impermeable backing membrane of Eudragit S100 was therefore incorporated into the matrices. Eudragit S100 was used as a backing membrane because of its hydrophobicity property. Eudragit S100 is an anionic $\mathrm{pH}$-sensitive copolymer that can be dissolved at $\mathrm{pH} 7$ [10]. In preliminary studies, it was found that the Eudragit S100 films were brittle and could not be processed into elastic films. Therefore, DBP was used as a plasticizer to reduce the brittleness, impart flexibility, and increase toughness, strength, tear resistance, and impact resistance of the films. The studies revealed that the addition of DBP $40 \% \mathrm{w} / \mathrm{w}$ of polymer produces smooth, uniform, and flexible films. The thicknesses of Eudragit S100 backing layer was approximately $28 \pm 3 \mu \mathrm{m}$. The double-casting protocol employed in this study was able to produce the tightly bound, homogeneous and smooth surface bilayered patches. The patches of all formulation have good flexibility, strength, transparency, and smooth surface. The thickness of lidocaine $\mathrm{HCl}$ patches ranged between $164 \pm 15$ and $170 \pm 15 \mu \mathrm{m}$, and mass varied between $19.4 \pm 1.6$ and $19.6 \pm 1.5 \mathrm{mg} / \mathrm{cm} 2$ (data not shown). The thickness range was found to be satisfactory which should not cause any discomfort to patients when applied [45]. The lidocaine $\mathrm{HCl}$ content of all formulations was in the average range of 2.53 to 2.57 $\mathrm{mg} / \mathrm{cm} 2$ (the percentage labeled amount of 97.4 to 100.0) with a low standard deviation $(<3 \%)$. These results confirmed content uniformity of lidocaine $\mathrm{HCl}$ in the patches.

\section{Mucoadhesive properties}

Selection of polymeric matrix as potential buccal system required knowledge of mucoadhesive properties of patches. Therefore, the mucoadhesive properties in terms of maximum detachment force $\left(F_{\max }\right)$ and work of adhesion $\left(W_{\mathrm{ad}}\right)$ of blank and lidocaine $\mathrm{HCl}$ patches were characterized using a texture analyzer and presented in fig. 8 . All blank patches (polymer matrices with backing) showed appreciable work of adhesion and maximum detachment force, which ranged between 2.7-3.6 N.mm and 2.8-3.6 N, respectively. The addition of lidocaine $\mathrm{HCl}$ had no effect on the mucoadhesive properties of the patches compared to those of blank patches. The $F_{\max }$ and $W_{\text {ad }}$ of the patches had a tendency to decrease with the concentration of PVP in the patch. However, the $F_{\max }$ and $W_{\text {ad }}$ of free patches containing PVP at $20 \%$ and $40 \%$ were comparable. The patch containing $60 \%$ PVP had significantly lower $F_{\max }$ and $W_{\text {ad }}$ than those of patch containing $20 \%$ PVP $\left({ }^{*} \mathrm{P}<0.05\right)$. In contrast to the moisture absorption, the inverted relationship between the PVP concentration and the $F_{\max }$ and $W_{\text {ad }}$ of blank patches with a high coefficient of determination ( $R 2$ of 0.9882 and 0.9981 , respectively) is shown. However, there is no standard formula available for the mucoadhesive buccal drug delivery. This PVA/PVP patch containing $20 \%$ PVP seems to be appropriate, with a high degree of mucoadhesion.

Mucoadhesion can be defined as the adhesion between a polymer and mucus. For the mucoadhesion to occur, an intimate contact between polymer and mucus has to take place as a result of a good wetting of the matrix surface with saliva [1]. Therefore, the intensity of adhesion is closely affected by the moisture absorption of the matrices. PVA is a non-ionic polymer that possess mucoadhesive properties [46-48] because of numerous hydrogen bond forming groups, i.e., hydroxyl groups, contained in its structure. It has been proposed that the interaction between the mucus and hydrophilic polymers occurs by physical entanglement and chemical interactions, such as hydrogen bonding [46]. The interaction of PVA with PVP may possibly lower the mobility and flexibility of PVA molecules, resulting in a decrease in the physical entanglement of PVA and mucus, and bring about a reduction in the number of hydroxyl groups of PVA available to interact with the mucus. For these reasons, the PVA/PVP patch with a higher concentration of PVP displayed a lower mucoadhesive property than that with a lower concentration of PVP. These results agree with the study of Nafee et al. [13] which reported the decrease in in vitro residence time with rabbit intestinal mucosal membrane of PVA patch containing miconazole nitrate with PVP concentrations. On the other hand, Nappinnai et al. [14] reported that films fabricated with PVA and PVP K30 were able to retain the mucosa for a longer period, compared to the one prepared with PVA.
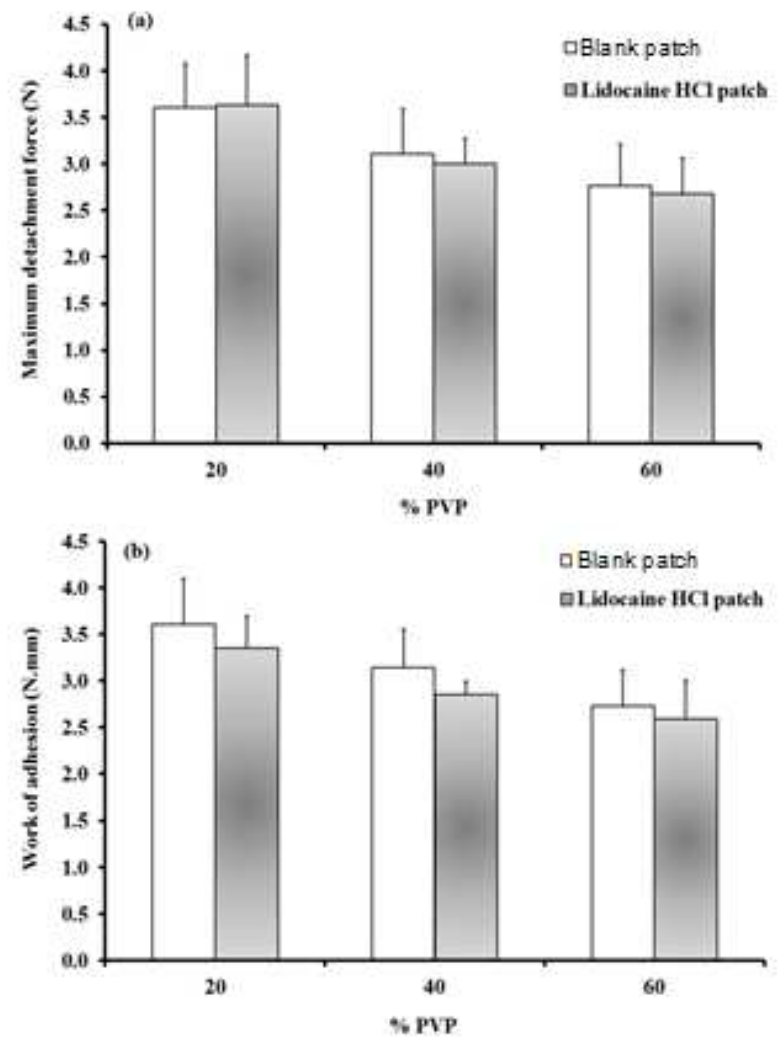

Fig. 8: Effects of PVP concentration on maximum detachment force (a) and work of adhesion (b) of blank patches and lidocaine $\mathrm{HCl}$ patches (mean $\pm \mathrm{SD}, n=5$ )

\section{In vitro permeation}

In vitro permeation study is one of the important tools to predict how the drug is going to behave in vivo. In the present study, in vitro permeation study was performed using porcine esophageal mucosa as permeation barrier because it has lipid composition which was comparable to that of the porcine buccal mucosa, but required a simpler preparation method [31]. The cumulative amount of drug permeated per centimetre squared was plotted against time as shown in fig. 9. As observed that the pattern of lidocaine $\mathrm{HCl}$ permeation started with an initial fast permeation followed by a slower permeation rate. The steady-state permeation fluxes were calculated from the slope of a linear portion of the curve using the zero-order and Higuchi models as shown in table 2 . It was found that the initial permeation rates fit well with the zero-order model (equation 1 ), with $R 2>0.98$. Based on the zero-order model, lidocaine $\mathrm{HCl}$ permeation rates ranged from $8.8 \pm 1.3$ to $10.2 \pm 1.8 \mu \mathrm{g} / \mathrm{cm} 2 / \mathrm{min}$. Insignificant difference between the initial permeation fluxes from lidocaine $\mathrm{HCl}$ patches prepared with different PVP concentrations was observed $(P>0.05)$. It was noted that, irrespective of the PVP concentrations in the polymer matrix, the cumulative permeation rates in the first $120 \mathrm{~min}$ of these lidocaine $\mathrm{HCl}$ patches were comparable; after that, the permeation rates gradually differed. At $240 \mathrm{~min}$, the cumulative permeation from LDC-P3 which was prepared with $60 \%$ PVP was significantly lower than that from LDC-P1 which was prepared with $20 \%$ PVP. These might be attributed to the higher hydrophilicity and swelling capacity of the patch prepared 
with $60 \%$ PVP. When the PVA-PVP layer is placed in contact with the mucosa, the drug compound migrates through the polymer and partitions across the interface of polymer/mucosa, which consequently migrates into the mucosa. The initial fast permeation may be attributed to the rapid diffusion of the drug to the surface of the film [16]. With time, swelling of polymer matrix occurred and varied the entanglement of polymeric pathways to control the drug diffusion from the matrix. Extensive swelling of the PVP contained in LDC-P3 might create a thick gel barrier, leading to increasing in mean diffusional path length. In addition, similar to transdermal delivery, the transmucosal delivery is a phenomenon governing the permeation properties and partitioning into the skin of drug and the drug release from the polymer matrix. Lidocaine $\mathrm{HCl}$ is a hydrophilic drug with $\log P \leq 0$ [23]. The fact that the latter showed slower permeation of drug from LDC-P3 compared to that of LDC-P1 patches could also be explained by the higher affinity of lidocaine $\mathrm{HCl}$ to the hydrated PVP, which lowered the tendency of lidocaine $\mathrm{HCl}$ to migrate and part into the mucosa.

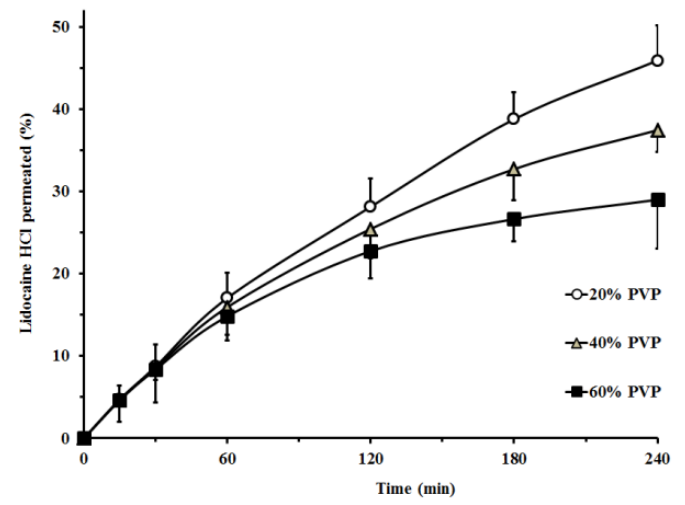

Fig. 9: Effect of PVP concentration on lidocaine $\mathrm{HCl}$ permeation from patches across the esophageal mucosal membrane (mean \pm SD, $n=3$ )

Table 2: Permeation characteristics of lidocaine $\mathrm{HCl}$ patches containing difference concentration of PVP

\begin{tabular}{|c|c|c|c|}
\hline \multirow[t]{2}{*}{ Formulation } & \multicolumn{2}{|c|}{ Lidocaine $\mathrm{HCl}$ permeation rate $^{*}$} & \multirow[t]{2}{*}{ Lidocaine $\mathrm{HCl}$ permeated at $240 \mathrm{~min}(\mu \mathrm{g} / \mathrm{cm} 2)^{a}$} \\
\hline & $K_{0}(\mu \mathrm{g} / \mathrm{cm} 2 / \mathrm{min})^{\mathrm{a}}$ & $K_{\mathrm{H}}(\mu \mathrm{g} / \mathrm{cm} 2 / \mathrm{min} 1 / 2)^{\mathrm{a}}$ & \\
\hline LDC-P1 & $10.2 \pm 1.8(R 2=0.999)$ & $76.5 \pm 15.1(R 2=0.945)$ & $1653.9 \pm 155.0$ \\
\hline LDC-P2 & $9.5 \pm 2.2(R 2=0.981)$ & $71.9 \pm 20.0(R 2=0.905)$ & $1349.2 \pm 96.3$ \\
\hline LDC-P3 & $8.8 \pm 1.3(R 2=0.993)$ & $67.3 \pm 10.1(R 2=0.947)$ & $1044.5 \pm 213.8$ \\
\hline
\end{tabular}

${ }^{*}$ calculated from 0 to $60 \mathrm{~min}{ }^{\text {amean }} \pm \mathrm{SD}, n=5$.

\section{CONCLUSION}

In the present study, mucoadhesive patches fabricated with PVA/PVP for buccal delivery of a hydrophilic compound were prepared and evaluated. Effects of PVP content in the PVA/PVP matrix on the mechanical, mucoadhesive and permeation properties were demonstrated. Incorporation of PVP in PVA/PVP matrix caused the decrease of crystallization degree of PVA, resulting in the decreased strength of polymeric matrix and mucoadhesive property of patches. Using lidocaine $\mathrm{HCl}$ as a model drug, lidocaine $\mathrm{HCl}$ was present as a molecular dispersion state in PVA/PVP matrices. The dissolved hydrophilic drug affected the mechanical property of patch. In vitro permeation results showed the insignificant effect of PVA/PVP ratio on the initial permeation fluxes across the mucosa of lidocaine $\mathrm{HCl}$ from the patches.

\section{ACKNOWLEDGEMENT}

The authors wish to thank the Center for Research and Development of Herbal Health Product, Faculty of Pharmaceutical Sciences, Khon Kaen University, for financial support.

\section{AUTHORS CONTRIBUTIONS}

All the authors have contributed equally.

\section{CONFLICT OF INTERESTS}

The authors report no conflicts of interest

\section{REFERENCES}

1. Park DM, Song YK, Jee JP, Kim HT, Kim CK. Development of chitosan-based ondansetron buccal delivery system for the treatment of emesis. Drug Dev Ind Pharm 2012; 38:1077-83.

2. Ikeuchi-Takahashi Y, Sasatsu M, Onishi H. Evaluation of matrix type mucoadhesive tablets containing indomethacin for the buccal application. Int J Pharm 2013;453:454-61.

3. Preis M, Woertz C, Schneider K, Kukawka J, Broscheit J, Roewer $\mathrm{N}$, et al. Design and evaluation of bilayered buccal film preparations for local administration of lidocaine hydrochloride. Eur J Pharm Biopharm 2014;86:552-61.
4. Adhikari SN, Nayak BS, Nayak AK, Mohanty B. Formulation and evaluation of buccal patches for delivery of atenolol. AAPS PharmSciTech 2010;11:1038-44.

5. Yehia SA, El-Gazayerly ON, Basalious EB. Design and in vitro/in vivo evaluation of novel mucoadhesive buccal discs of an antifungal drug: the relationship between swelling, erosion, and drug release. AAPS PharmSciTech 2008;9:1207-17.

6. Dixit RP, Puthil SP. Oral strip technology: overview and future potential. J Controlled Release 2009;139:94-107.

7. Patel VF, Liu F, Brown MB. Advances in oral transmucosal drug delivery. J Controlled Release 2011;153:106-16.

8. Bruschi ML, de Freitas O. Oral bioadhesive drug delivery systems. Drug Dev Ind Pharm 2005;31:293-310.

9. Guo JH, Cooklok KM. The effects of backing materials and multilayered systems on the characteristics of mucoadhesive buccal patches. J Pharm Pharmacol 1996;48:255-7.

10. Cui Z, Mumper RJ. Bilayer films for mucosal (genetic) immunization via the buccal route in rabbits. Pharm Res 2002;19:947-53.

11. Satishbabu B, Srinivasan B. Preparation and evaluation of buccoadhesive films of atenolol. Indian J Pharm Sci 2008;70:175-9.

12. Saxena A, Tewari G, Saraf SA. Formulation and evaluation of mucoadhesive buccal patch of acyclovir utilizing inclusion phenomenon. Braz J Pharm Sci 2011;47:887-97.

13. Nafee NA, Ismail FA, Boraie NA, Mortada LM. Mucoadhesive buccal patches of miconazole nitrate: in vitro/in vivo performance and effect of ageing. Int J Pharm 2003;264:1-14.

14. Nappinnai M, Chandanbala R, Balaijirajan R. Formulation and evaluation of nitrendipine buccal films. Indian J Pharm Sci 2008;70:631-5.

15. Sadeq ZA, Rajab NA. Study the effect of different variables on the formulation of mucoadhesive buccal patches of captopril. Int J Appl Pharm 2017;9:16-21.

16. Peddapalli $\mathrm{H}$, Chinnala KM, Banala N. Design and in vitro characterization of mucoadhesive buccal patches of duloxetine hydrochloride. Int J Pharm Pharm Sci 2017;9:52-9.

17. Abouhussein DMN, El-bary AA, Shalaby SH, El-nabarawi MA. Chitosan mucoadhesive buccal films: effect of different casting solvents on their physicochemical properties. Int J Pharm Pharm Sci 2017;8:206-13. 
18. Abou Taleb MH. Thermal and spectroscopic studies of poly (Nvinyl pyrrolidone)/poly (vinyl alcohol) blend films. J Appl Polym Sci 2009;114:1202-7.

19. Jug M, Becirevic Lacan M, Bengez S. Novel cyclodextrin-based film formulation intended for buccal delivery of atenolol. Drug Dev Ind Pharm 2009;35:796-807.

20. Seabra AB, de Oliveira MG. Poly(vinyl alcohol) and poly(vinyl pyrrolidone) blended films for local nitric oxide release. Biomaterials 2004;25:3773-82.

21. Padula C, Nicoli S, Colombo P, Santi P. Single-layer transdermal film containing lidocaine: modulation of drug release. Eur J Pharm Biopharm 2007;66:422-8.

22. Malipeddi VR, Awasthi R, Ghisleni DD, de Souza Braga M, Kikuchi IS, de Jesus Andreoli Pinto T, et al. Preparation and characterization of metoprolol tartrate containing matrix-type transdermal drug delivery system. Drug Delivery Transl Res 2017;7:66-76.

23. Sawant PD, Luu D, Ye R, Buchta R. Drug release from hydroethanolic gels: Effect of drug's lipophilicity (Log $P$ ), polymer-drug interactions and solvent lipophilicity. Int J Pharm 2010;396:45-52.

24. Hu L, Silva SMC, Damaj BB, Martin R, Michniak-Kohn BB. Transdermal and transbuccal drug delivery systems: enhancement using iontophoretic and chemical approaches. Int J Pharm 2011;421:53-62.

25. Abu-Huwaij R, Assaf S, Salem M, Sallam A. Potential mucoadhesive dosage form of lidocaine hydrochloride: II. In vitro and in vivo evaluation. Drug Dev Ind Pharm 2007;33:437-48.

26. Ghosh S, Roy G, Mukherjee B. Dental mold: a novel formulation to treat common dental disorders. AAPS PharmSciTech 2009:10:692-702

27. Kohda Y, Kobayashia H, Babaa Y, Yuasab H, Ozekib T, Kanayab $\mathrm{Y}$, et al. Controlled release of lidocaine hydrochloride from buccal mucosa-adhesive films with solid dispersion. Int J Pharm 1997;158:147-55.

28. Varshosaz J, Karimzadeh S. Development of cross-linked chitosan films for oral mucosal delivery of lidocaine. Res Pharm Sci 2007;2:43-52.

29. Abu-Huwaij R, Assaf S, Salem M, Sallam A. Mucoadhesive dosage form of lidocaine hydrochloride: I. Mucoadhesive and physicochemical characterization. Drug Dev Ind Pharm 2007;33:855-64.

30. Okhamafe AO, York P. Studies of interaction phenomena in aqueous-based film coatings containing soluble additives using thermal analysis techniques. J Pharm Sci 1988;77:438-43.

31. Diaz-del Consuelo I, Jacques Y, Pizzolato G, Guy RH, Falson F. Comparison of the lipid composition of porcine buccal and esophageal permeability barriers. Arch Oral Biol 2005;50:981-7.

32. Diaz-del Consuelo I, Falson F, Guy RH, Jacques Y. Ex vivo evaluation of bioadhesive films for buccal delivery of fentanyl. J Controlled Release 2007;122:135-40.
33. Costa P, Lobo JMS. Modeling and comparison of dissolution profiles. Eur J Pharm Sci 2001;13:123-33.

34. Xiao S, Huang RYM, Feng X. Preparation and properties of trimesoyl chloride crosslinked poly(vinyl alcohol) membranes for pervaporation dehydration of isopropanol. J Membr Sci 2006;286:245-54.

35. Rajeswali N, Selvasekarapandian S, Karthikeyan S, Prabu M, Hirankumar G, Nithya $\mathrm{H}$, et al. Conductivity and dielectric properties of polyvinyl alcohol-polyvinylpyrrolidone poly blend film using non-aqueous medium. J Non-Cryst Solids 2011;357:3751-6.

36. Cassu SN, Felisberti MI. Poly(vinyl alcohol) and poly(vinyl pyrrolidone) blends: miscibility, microheterogeneity and free volume change. Polymer 1997;38:3907-11.

37. Powell MF. Lidocaine and lidocaine hydrochloride. In: American Pharmaceutical Association, editor. Analytical profiles of drug substances. Vol. 15. New York: Academic Press; 1986. p. 761-9.

38. Penido CA, Pacheco MT, Zangaro RA, Silveira LJr. Identification of different forms of cocaine and substances used in adulteration using near-infrared Raman spectroscopy and infrared absorption spectroscopy. J Forensic Sci 2015;60:171-8.

39. Aitken-Nichol C, Zhang F, McGinity JW. Hot melt extrusion of acrylic films. Pharm Res 1996;13:804-8.

40. Strawhecker KE, Manias E. Structure and properties of poly(vinyl alcohol) $/ \mathrm{Na}^{+}$montmorillonite nanocomposites. Chem Mater 2000;12:2943-9.

41. Badr Y, Mahmoud MA. Effect of PVA surrounding medium on ZnSe nanoparticles: Size, optical, and electrical properties. Spectrochimica Acta Part A 2006;65:584-90.

42. Eisa WH, Abdel-Moneam YK, Shabaka AA, Hosam AEM. In situ approach induced growth of highly monodispersed Ag nanoparticles within free-standing PVA/PVP films. Spectrochim Acta Part A 2012;95:341-6.

43. Mutalik S, Udupa N. Glibenclamide transdermal patches: physicochemical, pharmacodynamic, and pharmacokinetic evaluations. J Pharm Sci 2004;93:1577-94.

44. Rowe RC, Sheskey PJ, Quinn ME. Handbook of pharmaceutical excipients. $6^{\text {th }}$ ed. Gurnee (IL): Pharmaceutical Press; 2009.

45. Karki S, Kim H, Na SJ, Shin D, Jo K, Lee J. Thin films as an emerging platform for drug delivery. Asian J Pharm Sci 2016;11:559-74.

46. Salamat-Miller N, Chittchang C, Johnston TP. The use of mucoadhesive polymers in buccal drug delivery. Adv Drug Delivery Rev 2005;57:1666-91.

47. Sudhakar Y, Kuotsu K, Bandyopadhyay AK. Buccal bioadhesive drug delivery-a promising option for orally less efficient drugs. J Controlled Release 2006;114:15-40.

48. Morales JO, McConville JT. Manufacture and characterization of mucoadhesive buccal films. Eur J Pharm Biopharm 2011;77:187-99. 